\title{
Smart University Library Management System Based on Internet of Things
}

\author{
Sivana Salahadin Muhamed ${ }^{1,2}$, Aso Mohammad Darwesh ${ }^{3}$ \\ ${ }^{1}$ Department of Computer Science, College of Science and Technology, University of Human Development, \\ Sulaymaniyah, KRG, Iraq, ${ }^{2}$ Department of Computer, College of Science, University of Sulaimani, Sulaymaniyah, KRG, \\ Iraq, ${ }^{3}$ Department of Information Technology, College of Science and Technology, University of Human Development, \\ Sulaymaniyah, KRG, Iraq
}

\begin{abstract}
A B S T R A C T
With the innovation of new technologies, many life concepts have been changed. However, libraries remain the same in many sides while the main role of libraries has been changed and new references may not need a classical library as it was 50 years ago. In the same time, library services can be improved using Internet of Things (loT) to increase user satisfactions. In recent years, there has been arisen in the diversity of implementation based on radio-frequency identification (RFID) systems and has been successfully utilized in several areas such as health care and transportation. RFID-based library management system will let rapid transaction flow for the library and could prove instant and longterm benefits to library in traceability and security. To solve the problem that it is inconvenient to find references in the traditional library, a kind of reference positioning system using RFID technology is designed to achieve fast search references in the library. Searching and sorting misplaced references are a hard task often carried out by the librarians. In this paper, the performance of RFID reader motion and tags allows fast transaction flow and easily handling the process like references borrowing from library can be done using RFID technology and users will get notified using Global System for Mobile. Two big issues have been exposed and tried to find the best solution for them, first is the management process of any library, from user management to shelving system and the second one is the data and reference security. The results show that the system can quickly find the references that bookworms hid, and the references are not timely put back on the shelves. Furthermore, the new library hall design and loT-based system improve the security.
\end{abstract}

Index Terms: Global System for Mobile, Internet of Things, Library Security, Library System, Radio-Frequency Identification

\section{INTRODUCTION}

Application of information technology in libraries has always been a boon to improve the quality and delivery of information services to the users. One technology is

\begin{tabular}{|l|l|}
\hline Access this article online \\
\hline DOI:10.21928/uhdjst.v4n2y2020.pp63-74 & $\begin{array}{l}\text { E-ISSN: 2521-4217 } \\
\text { P-ISSN: 2521-4209 }\end{array}$ \\
\hline
\end{tabular}

Copyright $(\odot 2020$ Muhamed and Darwesh. This is an open access article distributed under the Creative Commons Attribution Non-Commercial No Derivatives License 4.0 (CC BY-NC-ND 4.0) the radio-frequency identification (RFID) technology [1]. The technology of RFID has been innovated by Charlie Walton [2]. RFID is a technology incorporates the use of electromagnetic or electrostatic pairing within the radio frequency $(\mathrm{RF})$ parcel of the electromagnetic range to uniquely identify an object, animal, or person. It is an automatic identification method where data can be stored and retrieved remotely using devices like RFID tags. The tag is also called as an "electronic label," "transponder," or "code plate," is made up of an RFID chip attached to an antenna, transmitting within the kilohertz, megahertz, and gigahertz ranges [3]. Library is an important place for

Corresponding author's e-mail: Sivana Salahadin Muhamed, Department of Computer Science, College of Science and Technology, University of Human Development, Sulaymaniyah, KRG, Iraq/Department of Computer, College of Science, University of Sulaimani, Sulaymaniyah, KRG, Iraq. E-mail: sivana.salahadin@uhd.edu.iq 
people to acquire new knowledge. Especially in today's era of knowledge explosion, it has become the important basic survival condition if we want to keep up with the trend of the times to gain more knowledge from references. The number and categories of library references also refresh the record in time. On the one hand, people can choose a targeted reference, on the other hand, large number of references no doubt increases the difficulty of library managers and readers when query and retrieve references. Using RFID technology in the research of library, shelf positioning system can help library information management [4]. With the maturity and popularity of the RFID technology, using the RFID technology can not only solve the contradiction between the librarians and the readers but also can improve the work efficiency of the librarians [5].

RFID is the latest technology that is used in library theft detection systems [6]. RFID-based system has been designed and developed to replace the existing library barcoding system and also the barcode can be damaged. This system allows the librarians to limit the spent time that's required for checking barcodes during charging and discharging process.

The RFID-based library management system (LMS) facilitates the quick issuing, reissuing, and returning of references with the help of RFID enabled modules. It directly provides reference information and library member data to the LMS and does not want the manual typing. It additionally provides monitoring and searching system. The monitoring module will constantly monitor the movement of references over the gates, in order that the references taken out without previous issuing will be followed out simply and will alert the librarians. The searching module gives the quick searching of references utilizing RFID reader. The physical location of the references may be simply located using this module [7]. Like any other system, this system will also have some problems that need to be solved, and these are problems such as the loss of references and the misplace of references place, the difficulty in finding the reference, also as well as stealing the references and giving them without the knowledge of the library employee, and an secure the references and users information.

\section{SHELVING SYSTEM}

To make library systems, efficient and successfully operational RFID solutions can be used to reduce operating costs through reducing the labor costs, enhancing automation, refining tracking and tracing, and inhibiting the loss of resources under any conditions. The system based on RFID is a unique concept by itself. Due to the fact that improved organization of references and resources becomes possible, resources are not lost, stealing is avoided, and customers are served on time and correctly [8]. Imagine a library where each reference has its own place on a particular shelf. Borrower like to take a reference off the shelf, there are some people who place back the reference in the right place, but many people either leave the references in some corner of the library or return them to the wrong places. This later situation is hard to identify and can make librarian's frightening [8]. Searching and sorting misplaced references are a difficult task often carried out by the library personnel. Quite often, librarians are busy with searching misplaced references which are left in wrong locations by library users. To overcome this, RFID-based intelligent shelving system has been proposed to provide an efficient mechanism of references management monitoring between the RFID reader and the references [9].

In this paper, we are aiming to create library system using this progressive RFID technology, which can track the references, whether they are issued or they are in library. RFID can be utilized for library circulation operations and theft detection systems.

\section{SECURITY AND PRIVACY OF RFID}

However, the rapid growth of RFID has raised serious privacy concerns over these years. Since RFID readers and tags communicate through a wireless channel, the messages exchanged in between, may be susceptible to eavesdropping or interception. Moreover, tags response to a reader's interrogation without the knowledge of their carriers [10]. Using encryption could be a perfect way to secure the contents of the information that is transmitted so that indeed in case an unauthorized person eavesdrops on the communication, the cipher text would not detect important information unless the key has moreover been compromised [11]. There is a need of a secure, safe, system that can facilitate the manager with the features that include monitoring the employee's communication. In this paper, we employed two different encryption algorithms, namely, triple data encryption standard (3-DES) and Message Digest 5 (MD5) to encrypt the data of system. RFID tag is used for the authentication process of verifying that identity.

\section{LITERATURE REVIEW}

To know the latest development in the area of RFID technology and its applications in libraries, the literature 
available in primary and secondary sources of information have been meticulously scanned and summary of some of the studies has been enumerated here. Most of the articles discussed about the RFID technology, its components, and its usage in managing library activities which are still at initial stage of implementation at many libraries.

Sivasankar et al. (2020), in this context, the RFID technology is used to manage smooth circulation in the library, in addition to ensuring the security of the books. Furthermore, the implementation of RFID in the library area can save the time of patrons and library staff. RFID technology helps libraries improve customer satisfaction with self-service experience and increases employee efficiency by multiple value-added services. This paper illustrates the comprehensive application of RFID technology in the library domain with a case study of migration RFID systems implemented in the Scientific Information Resource Division [6].

Bomble et al. (2020) in this research have found that RFID is serving a variety of functions relating to stock management, security, and issuing. RFID is one such technology which can be used not only for security purpose but also in circulation operations, location of library materials, stock management, and high-speed inventorying. Moreover, the application promises to increase efficiency, productivity and enhance user satisfaction. RFID technology helps the library management to offer more secure and foolproof library services to their users. It helps a librarian in providing the users with optimum utilization of resources. The research is implementation project in Central Library, where the library staff was able to use the findings to good effect to create a business plan. It is critical to teach library staff and library users around RFID technology before implementing a program. It may be better for librarians to observe developments in RFID until the cost of tags comes [3].

Mohammed et al. (2019) described that a book tracking RFIDbased system has been designed and developed to replace the existing library barcoding system. This system allows the librarians to limit the spent time that's required for checking barcodes during charging and discharging process. Advance, this technology has been upgraded by inserting Global System for Mobile (GSM) features to inform and alarm the borrower book with the due date of book return additionally determine the related fine if the due date is surpassed [12].

Gandu et al. (2019) described the deployment of smart devices in Internet of Things (IoT) applications that are expanding with huge pace causing serious security concerns, because it exchange most of private data. To counter that security issues in low-resource applications, lightweight cryptographic algorithms have been presented in recent past years. In this paper, they propose effective hardware design of piccolo lightweight algorithm uses 64 bits block size with variable key size of length 80 and 128 bits. This paper presents novel hardware architecture of piccolo-80, to supports high-speed RFID security applications. Different design procedures are there to optimize the hardware metrics trade-off for specific application [13].

Snehalatha et al. (2018), this paper proposes the design and implementation of smart library for digitalizing the library using Io $T$ without any human interruption. Implementation of this framework is based on RFID technology, that is, RFID tags are placed on books and RFID reader is used to read these tags. This study is to atomize the library such as allowing fast transaction flow and easily handling the activities such as process of issuing and return of book from library can be done using RFID technology and user will get notified using GSM. RFID is used to check the availability, misplacement of book, provide anti-theft, and location of book. Book availability and location of book can be checked on webpage. Information of each user card will be maintained on database and update automatically using IoT [14].

Mahdi et al. (2018) examined the role of the IoT in libraries and educational centers as the new technology. Since new technologies have raised library services user expectations, so librarians should be aware of the various aspects of IoT in libraries and services. They should also be trained about IoT security issues in libraries and the lifestyles of users. The IoT will continue to affect libraries and their services through building, collection management, instruction, data security, and information literacy and so on. This study also aims to introduce readers to new IoT technology that can help libraries enhance their services and improve user satisfaction [15].

Ajay (2017) describes the potential of RFID technology in facilitating efficient library operations and demonstrates that RFID can be used in libraries to ensure security and facilitate innovative services and highlights key issues that needed to be addressed to achieve successful implementation of RFID in libraries and also examines key challenges in the deployment of the technology [16].

Santha et al. (2016) described that the application of GSM technology for documents identification was examined. The 
mobile pervasive technology can be used by the libraries to serve their patrons to avail the library services in an effective and efficient way. The libraries should also use mobile popular technologies to support their customers as well as the patrons to allow better use of the library services. When implementing this technique, the services offered the libraries to the user will be more efficient and effective [17].

Sun et al. (2012) in their paper entitled "A proposed model for library stacks management" developed a new stacks management model called "parent-child-grandchild model" by changing the layout of the book stacks, the management principles, as well as by employing the RFID. In such a model, book stacks are divided into three sections, one large ("parent"), one medium "child," and one small "grandchild." The three sections comprised the entire printed collection of a library, representing different functions and use of the stacks. They pointed out that a library needs a good RFID support facility which helps the library staff to manage printed material more effectively and library users to find the physical location of books. They discussed the transaction processes, production processes, governance processes, interaction process, and facilitation process of RFID. They concluded that it is a revolutionary idea to implement the new model, which attempts to achieve not only better stack management but also a more friendly and attractive library image [18].

\section{PROBLEM STATEMENT}

Due to huge amount of references in libraries, working on them in terms of management and security becomes critical. Using new technologies can help solve many of these problems. Furthermore, recently, COVID-19 wakes up the world that everything must be managed differently or must be possible to manage it in classical and modern ways. Smart library systems become a new model to manage libraries. However, still some issues must be exposed. In this research, we focused on two major ones which are decreasing time consumption and save the privacy. We use IoT-based technologies to implement a modern system of LMS. Basically, we focused on using RFID and GMS. We use RFID to retrieve resources' information and find their position. Furthermore, we suggest a new design for a library to implement our system. Then, we encrypt all library data using two algorithms 3-DES and MD5 to prevent any data stolen. Finally, we design GSM system for library to direction the system and notify borrowers with a text message for important requirements.

\section{NOVELTY OF WORK}

1. New design for the library including different types of references each in a separate section in the library.

2. Shelve references and puts a misplaced reference in the correct place. That is by classifying the references shelves according to the types and subject of references and placing each reference in the shelf of its own class that helps put the reference in the correct place after its return by the borrower.

Using security techniques to prevent any attacked and stolen the data of the system. We use a 3-DES and MD5 algorithm to encrypt and decrypt all stored data.

3. Using IoT to improve the library system in wasting time, shelving system, and stolen of valuable references.

\section{IMPLEMENTATION OF RFID IN LIBRARY}

Basically in library systems, tags ID should be compared with the database to find the reference location and its details. The database saves a set of original information that includes the tag ID, reference title, reference class number, and author name. The database of resources information is different to the borrowing one. Each user must have an RFID card which is connected to a record in the database that contains all details. Whenever the user needs borrowing any reference, employee scan his/her ID card first then select the operation (Borrow in this case) and finally scan the reference. In the software, we are maintaining the separate database for issuing or returning reissuing the references. Each user has RFIDs card and in the library software for that id is stored with the user detail. The RFID readers read the tags and it checks if the user and reference data found in the database. If both are there, then the user can issued the particular reference. Any reference not assigned to any user cannot be bringing outside the library. If not, the gate in which the non-assigned reference passed detects, issue an alarm, and informs the security and the employees by message. The library software is implemented using. NET platform using $\mathrm{C} \#$ as a front end and Microsoft Access as back end to maintain the database.

\section{METHODOLOGY}

\subsection{RFID Library System Design and Content}

The implementation of the RFID systems has impacted on the library in various ways. In our model, we design the library system to facilitate handling references and easy to use by library employees and readers. 


\subsubsection{Library sections}

According to the types of resources, there are three zones in the library (read only, read and copy, and borrow), as explained in Fig. 1. At the entry of each zone, there are two lights red and green informing the user and the librarian to allow/disallow entrance of the user depending on the reference type, the user can enter only that zone. In case of borrowed type of resources, the borrower will be registered by the employee of the library which allows him/her to take the resources outside the library and the exit door will opens successfully. The readers are installed in different positions at the library doors to detect the references when someone tries to steals references, as explained in Fig. 1. Fig. 2 shows the hardware implementation of the system.

\subsection{The System Can Solve this Problem 8.2.1. Shelving references using RFID}

With the RFID, it becomes very easy, to shelve references and put a misplaced reference in a correct place. Discharged references can easily be separated according to the class number and location number. That is by classifying the references shelves according to the types and subject of references, and placing each reference in the shelf of its own class, with a RFID reader for each shelf it is programmed for the reference class of specific shelve that helps put the reference in a correct place after its return by the borrower. The system is programmed as follows: The references are scanned through the RFID reader of the shelve when the reference is placed in the correct shelve, the green light is turned on, otherwise, the red light is turned on and an attempt is made again to search for the correct place of the reference until the green light is turned on. Thus, the state of loss of references and lack of knowing its correct location after its return is decreased. We suggest this idea of shelving reference by RFID and implement it in the system as one of our research contributions, as shown in Fig. 3.

\subsubsection{Theft detection and alarm access control system}

The security gates have been installed at the exit gate of the library. RFID technology is a high-performance anti-theft technology, it detects any resources that has not been checked out by librarian and cannot pass through the exit door. Fig. 4 shows the hardware implementation of exit gate.

\subsubsection{Saving time at the circulation counter}

Circulation includes check-out, check-in, and renewal of borrowing. It generally takes 1-2 min to complete a single transaction when the task is performed manually, while the same transaction takes place within 5-10 s with the RFID system. A further advantage is that if the user has five items to check-out or check-in the transaction can be simply completed within single cycle.

\subsubsection{Save references and user privacy}

The references and user information need to be secure and privacy in the database to avoid any attacked and stolen

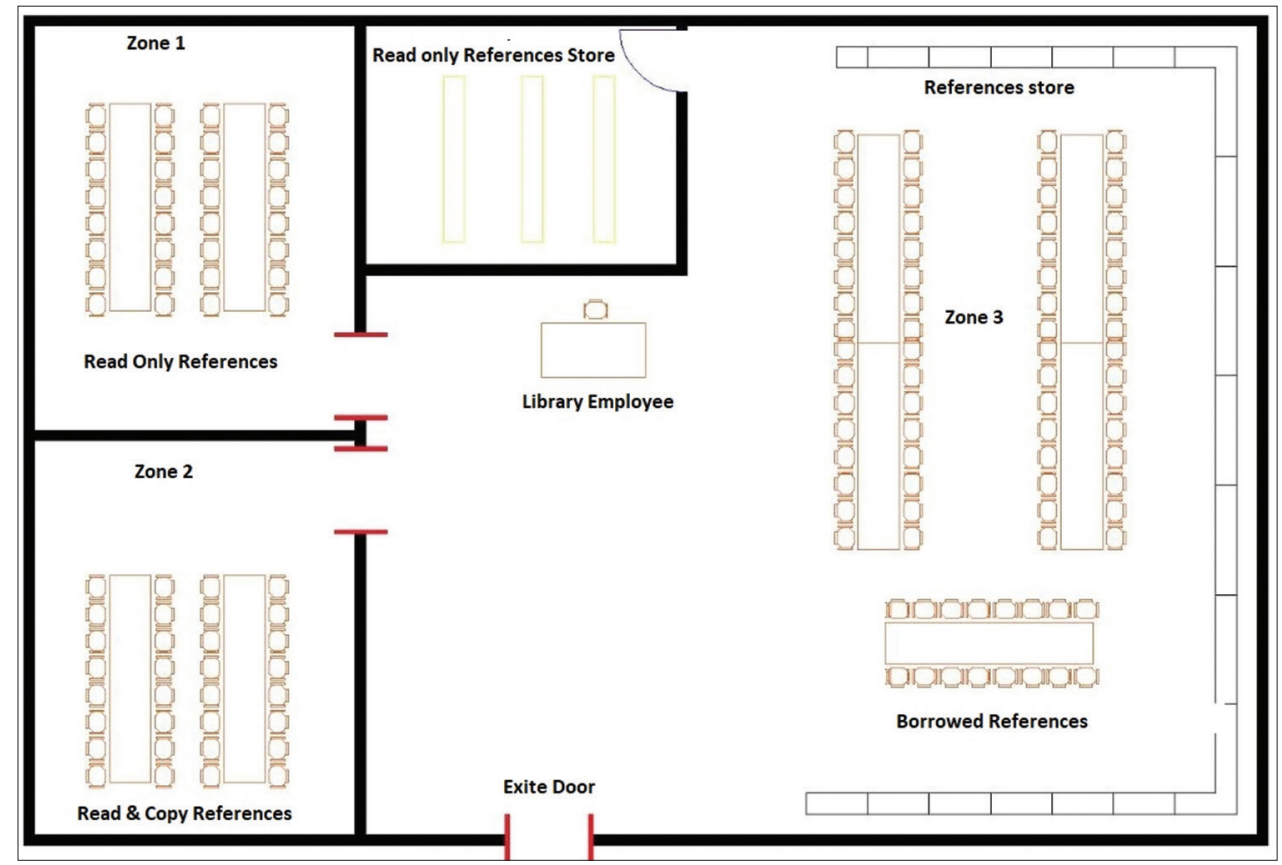

Fig. 1. The design of system. 
data of the system. To prevent this issue in this system, we use 3-DES and MD5 algorithm to encrypt and decrypt stored data. The data will be encrypted and then stored in the database, and then, we need retrieve the data decrypted and display on the interface. Data encrypt and decrypt code shown in Figs. 5 and 6.

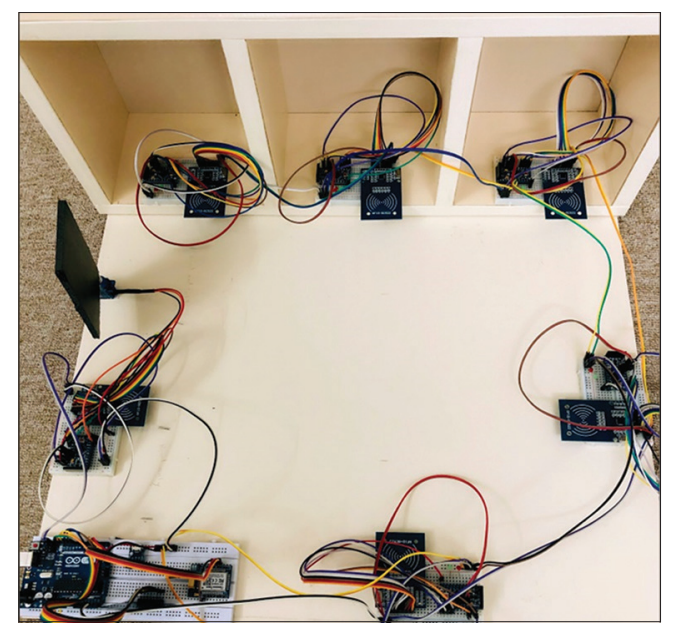

Fig. 2. Hardware implementation of the system.

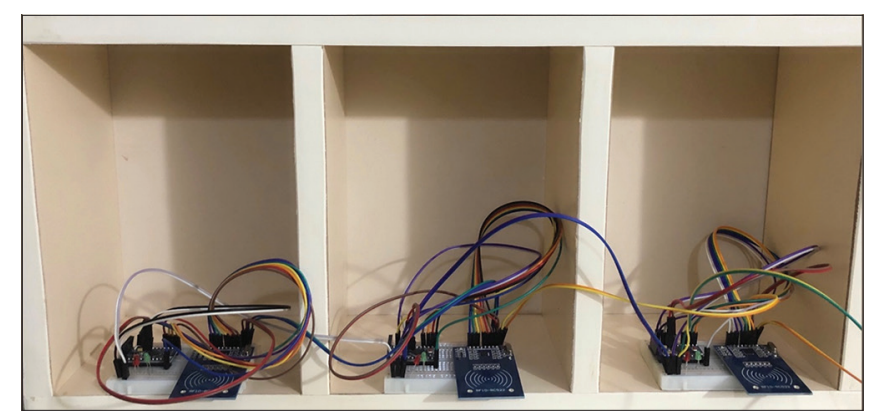

Fig. 3. Shelving references of the system.

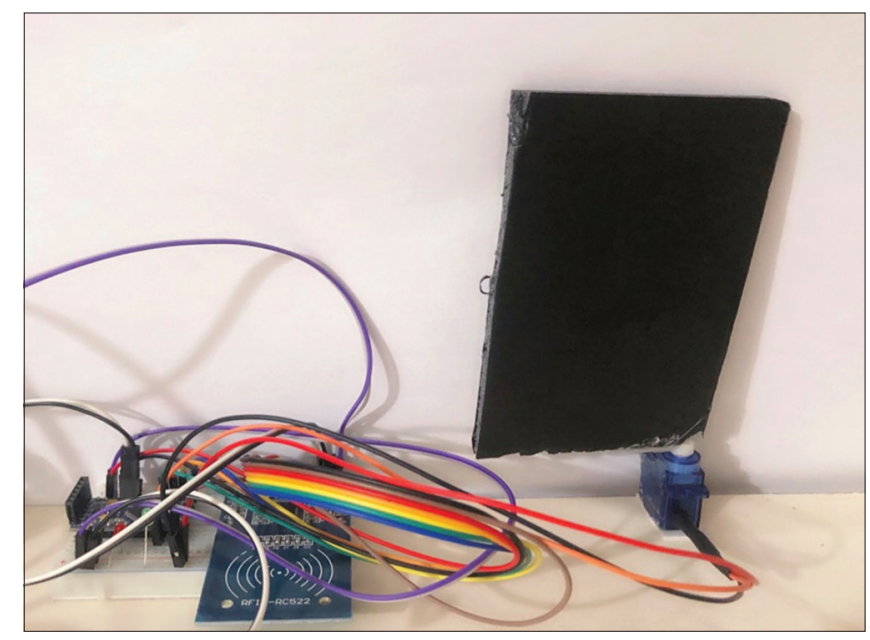

Fig. 4. Hardware implementation of exit gate.

\subsubsection{Using GSM system}

A GSM modem that shows in Fig. 7 is used for sending a message to the borrower regarding the last due date of returning the reference. The system will help to reduce the waiting time of users in queue for issuing and returning of references in the library. The message is shown in Fig. 8.

\section{THE DESIGN OF THE SYSTEM}

The RFID system includes related hardware devices and application software system, whose function and services must be connected with the library existing management system after it has been used in practice [19]. The flow diagram shown in Fig. 9 explains the functioning of the proposed library system. The librarian use RFID card for login to the system, then scan user's RFID tag. Finally, scan reference's RFID tag and set the reference as borrowed and search for another reference if user has any more reference.

\subsection{The Design of the Main System Interface}

Because the system consists of six modules, references information module, user information, namely, the borrowing module, the report module, history module, and the setting module, so these fife parts should be displayed in the main interface. One can understand the functions of every module clearly through the main interface. Main interface describes in Fig. 10.

\subsection{The Design of References Information Module}

The main function of this module is to manage the references, including add, delete or modify the information of references, display the status, or set the reference as a borrow reference for borrower user. Also can search for references by Reference tittle, Reference author, and Can search by RFID tag of reference. Reference information and details are shown in Figs. 11 and 12.

\subsection{The Design of User Information Module}

Each user use him/her RFID card of the university, we can use this card for library also by insert all users data in to the database and when an user need to borrow a reference s/ he need just swipe him/her RFID card and display him/ her information. The user information module is shown in Fig. 13.

\subsection{The Design of Borrow Module}

The main function of this module is to borrow references. To borrow references successfully, the borrower should swipe him/her RFID card, and click the borrow button, finally, swips RFID tag of the reference. The system will 


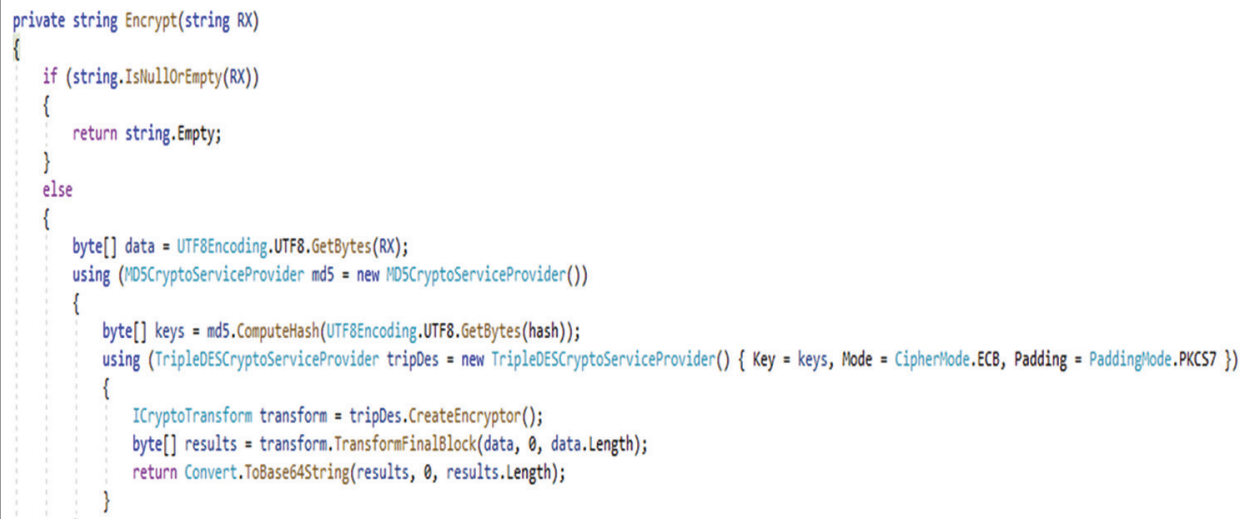

Fig. 5. Encrypt code.

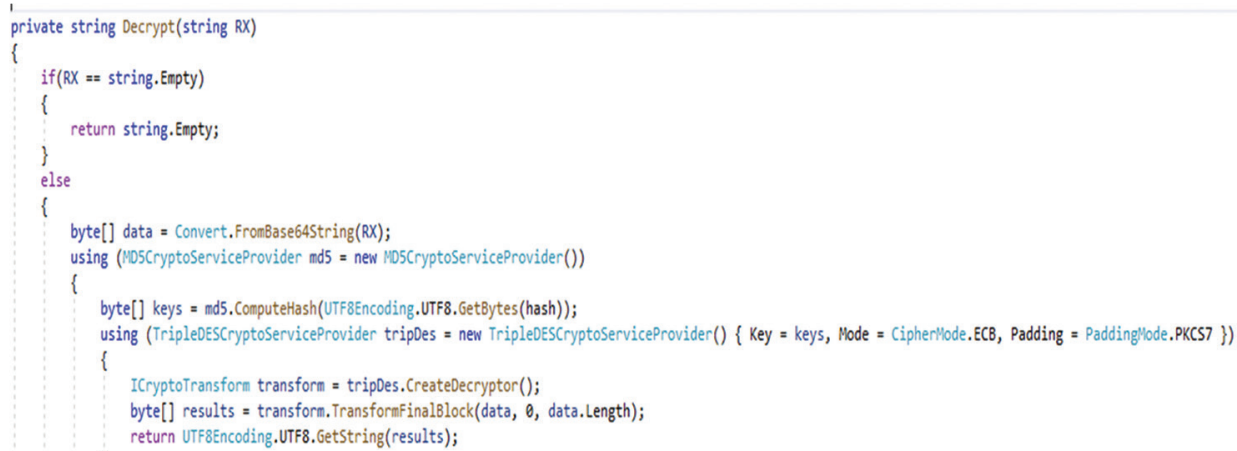

Fig. 6. Decrypt code.

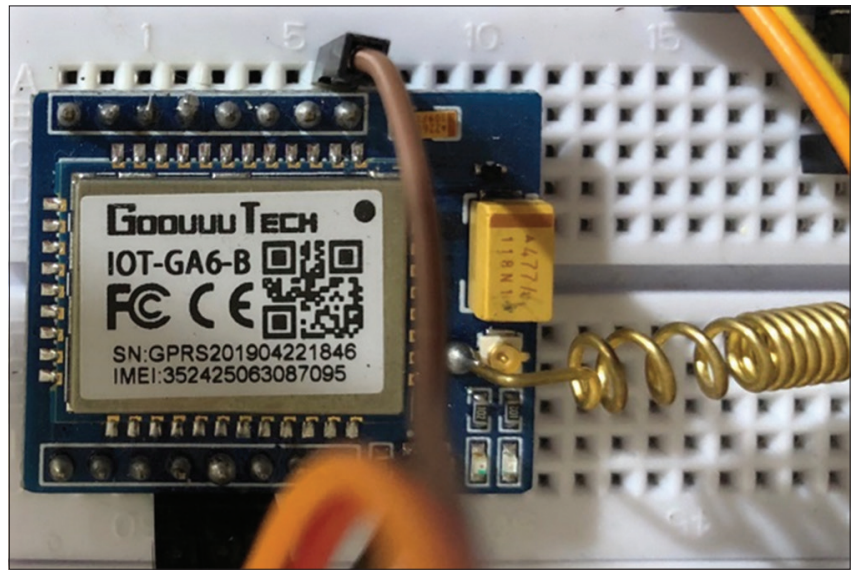

Fig. 7. GSM device.

build relations between the user and the borrowed references. Moreover, the references will added to list of borrowed

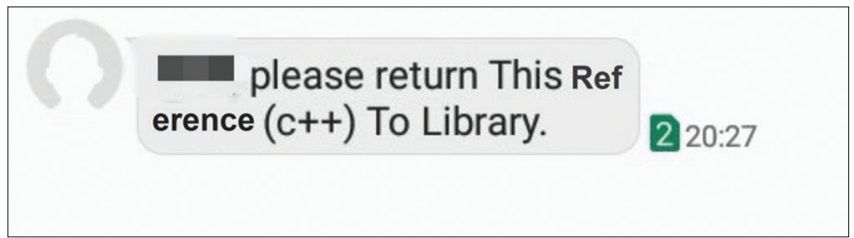

Fig. 8. System message.

reference, and they cannot be borrowed any more if there is only one copy of the reference in the library. Borrow module is shown in Figs. 14 and 15.

\subsubsection{Return reference}

The borrow module contains a return part that contains list of borrower that should return references in due date. This part shows who should return which references each day and who did not return his/her borrowed reference in specific date. If the reference returned in the current date 


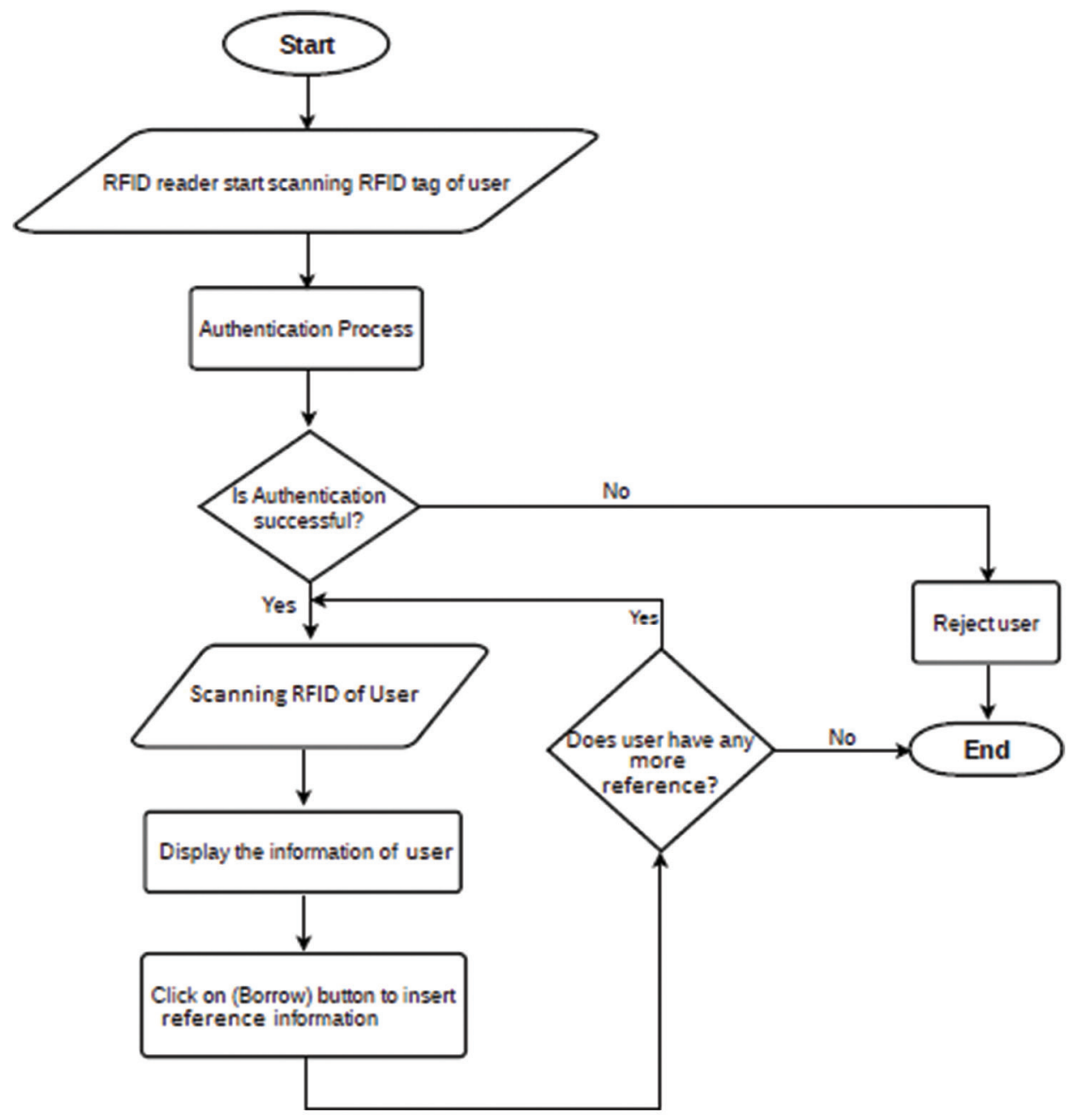

Fig. 9. The flow diagram of system.

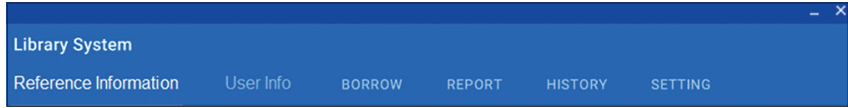

Fig. 10. Main interface of system.

delete user from borrowed list, or the system will send SMS automatically to the user for return the reference to library. It is also possible to send SMS message again manually. The reference returning part is shown in Fig. 16.

\subsection{The Design of Report Module}

The report is an important part in any system. In this system, the report design shows the number of references, number of borrowed ones, top 10 of the most borrowed references and top borrowers, number of references per language, and some other reference specific data. The report module is described in Fig. 17.

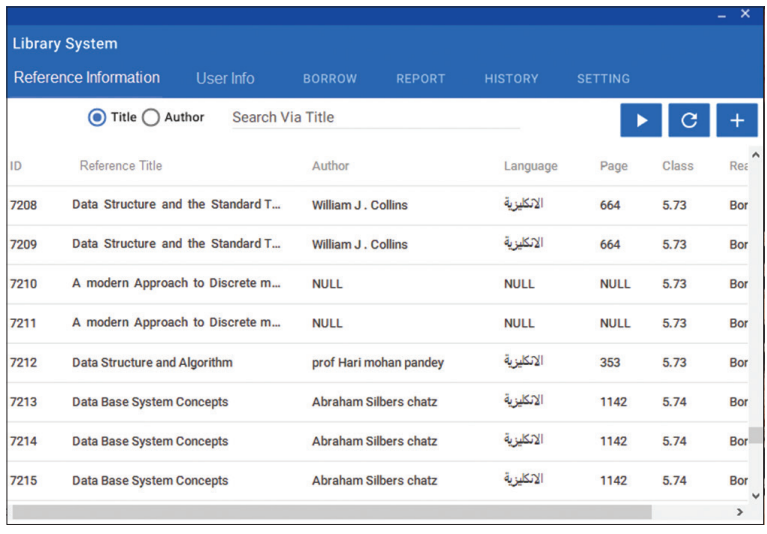

Fig. 11. List of references.

\subsection{The Design History Module}

This module contains all history of the system such as add reference, delete reference, borrow reference, and return 


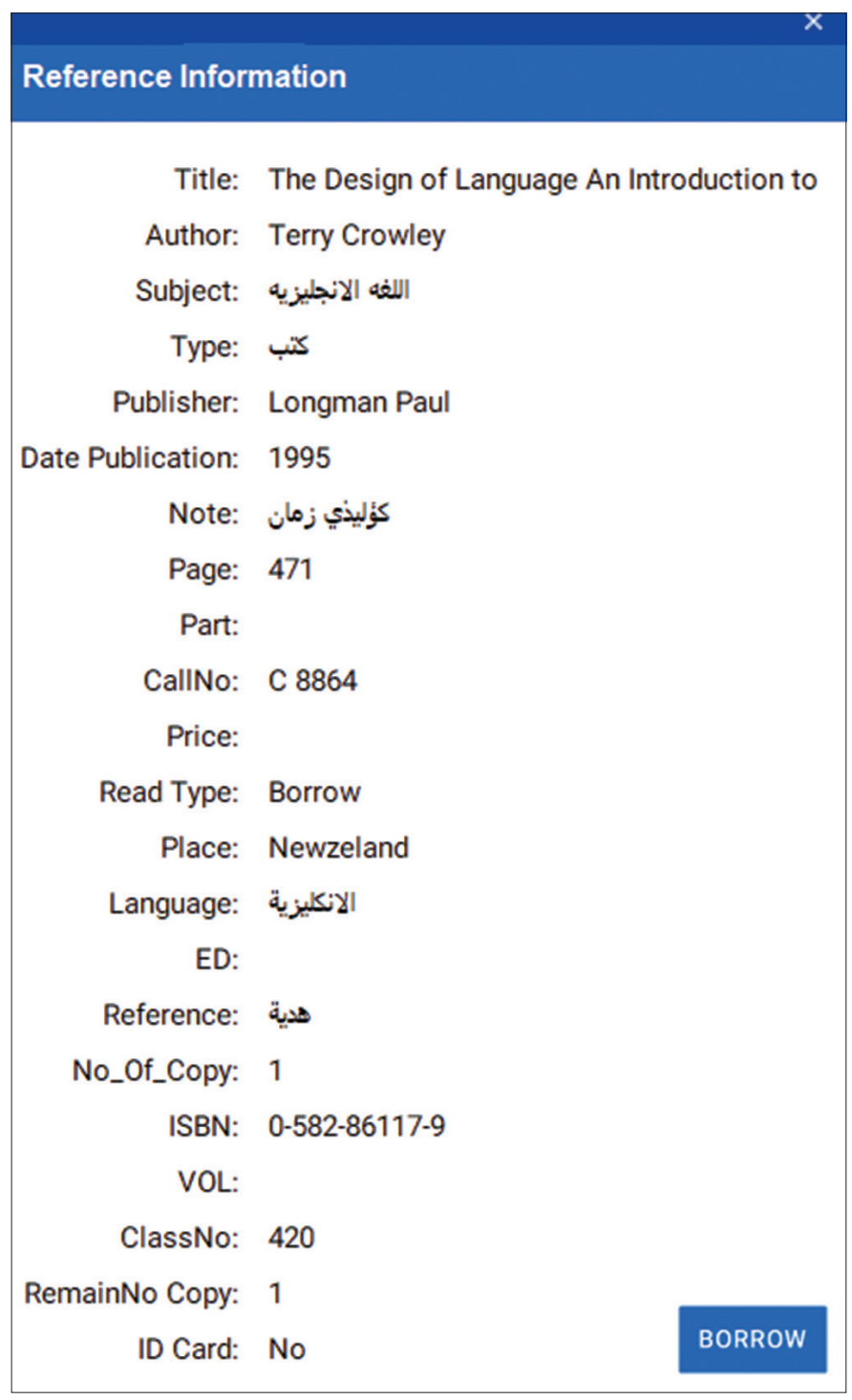

Fig. 12. Detail of reference.

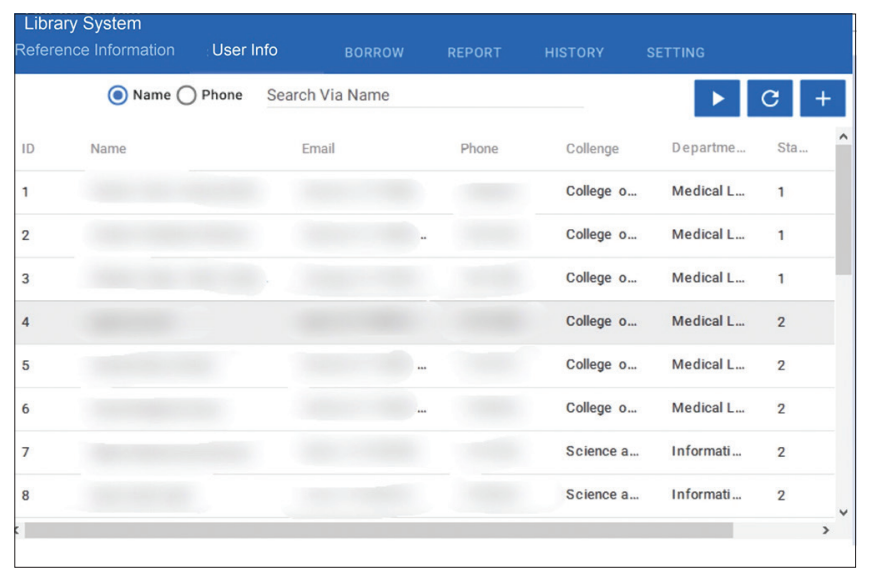

Fig. 13. List of user information.

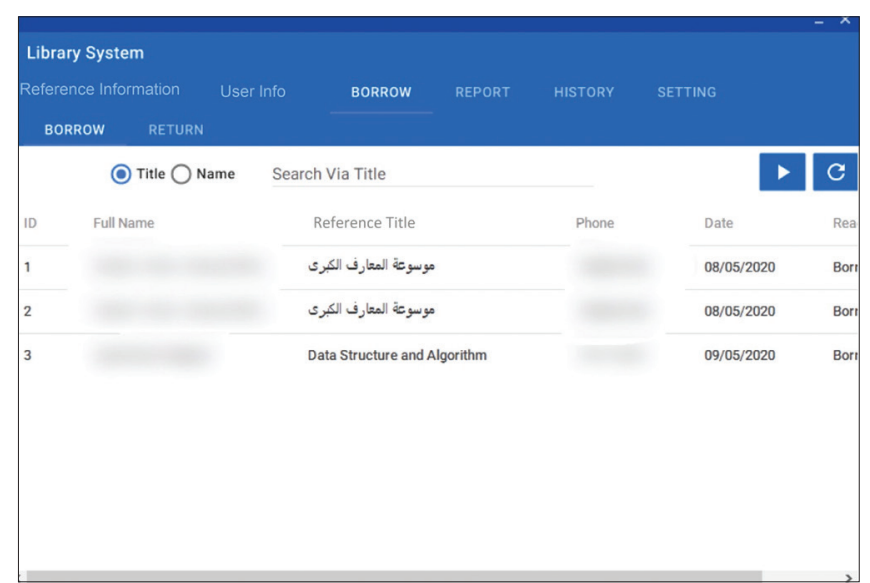

Fig. 14. List of borrowed reference.

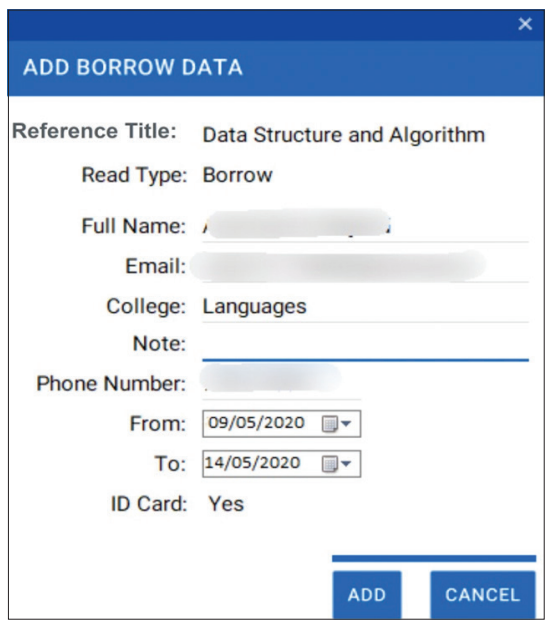

Fig. 15. Borrow process.

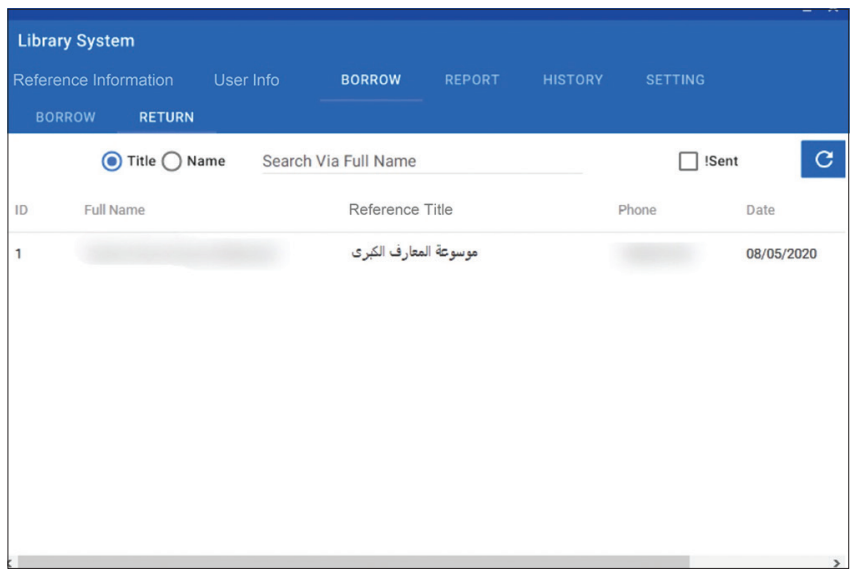

Fig. 16. Return reference part.

reference and the name of user. The history shows as monthly and we can clear all data of this month. Fig. 18 shows history module. 


\subsection{The Design Setting Module}

The setting module contains of some part that shown in Fig. 19 that makes a system easy to control and use. Below explain parts of setting module.

\section{7. 1. Create user account}

The employee who uses the system should have his/her user account. To create an account, we need to assign a username and password linked to an RFID tag. The login to system just needs to swipe his/her RFID card and login to the system directly without insert username and password. Create user account shown in Fig. 20.

\subsubsection{Control system color}

In the setting part, we can control change the system color for red, green, or blue. Moreover, can check to dark theme to enable dark theme or uncheck to disable dark theme.

\subsubsection{Readering notification}

We can observe what the borrower doing and where is s/he in the library. By check on readering notification, any active

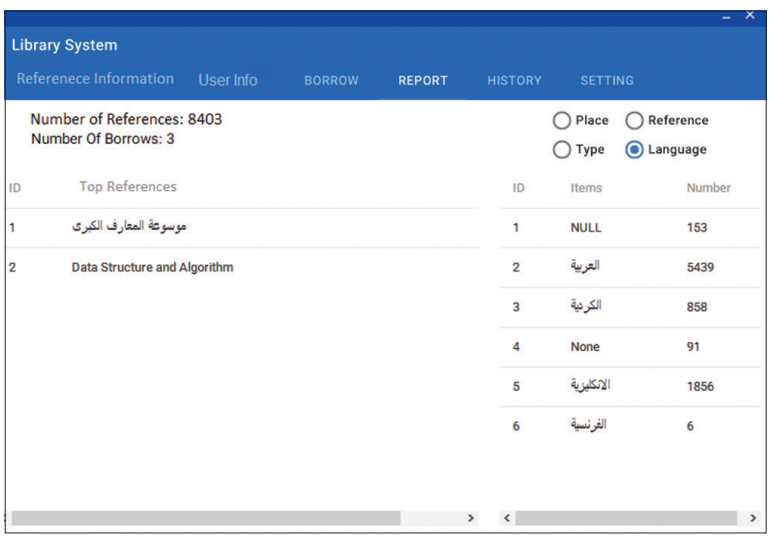

Fig. 17. Report module.

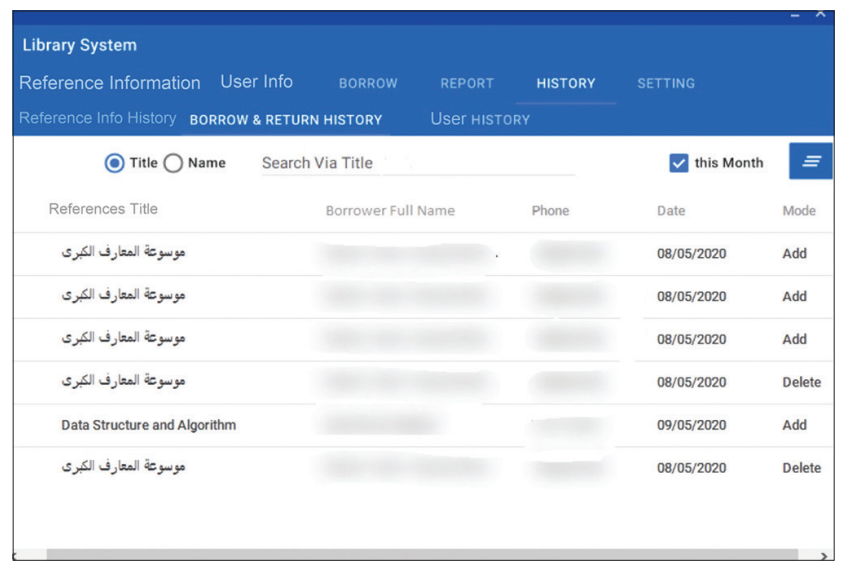

Fig. 18. History module.
RFID reader in the system will be notified when the borrower use this RFID reader.

\subsubsection{Auto-send SMS}

By check on auto-send SMS, the system will send SMS automatically for the borrowers who does not returned reference in current day to returned reference to library.

\subsubsection{Send SMS notification}

If auto-send SMS does not enabled, by check on this part, the system will notify a remember notification for a librarian every day to send the message to the borrower who did not return the reference at the appointed time to library. Fig. 21 shows SMS notification.

\subsubsection{Auto-connection}

When check in auto-connection, all the RFID readers in the system will connected automatically and do not need to connect manually by a librarian.

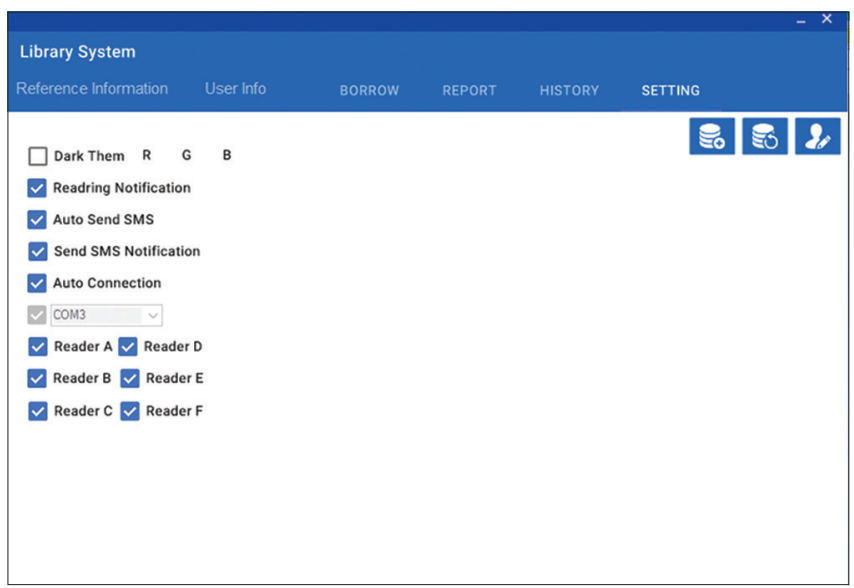

Fig. 19. Setting module.

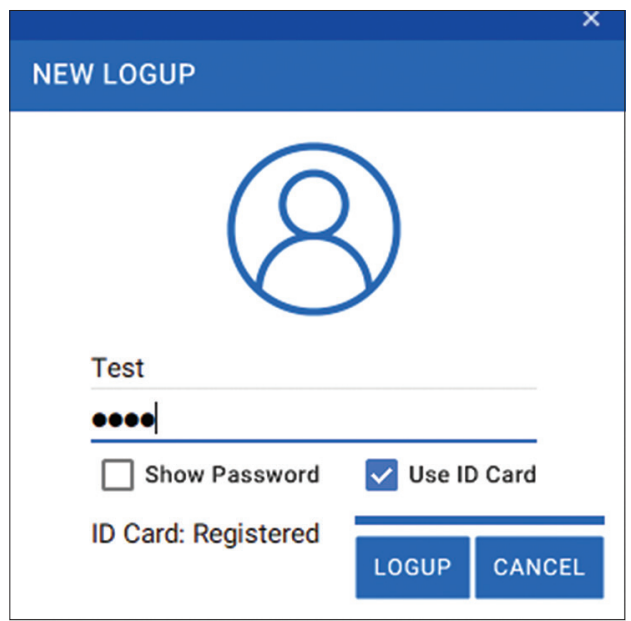

Fig. 20. Create user account. 


\subsubsection{RFID readers control}

In the setting part, we can control all the RFID readers of the system. We decide which RFID reader is work or not. In the case, when any problem occurs in the library, we can control each RFID reader of the system to stop of working or not.

\subsubsection{Backup system}

The system can back up the database and by default encrypt the data. If we need to backup database without encryption,

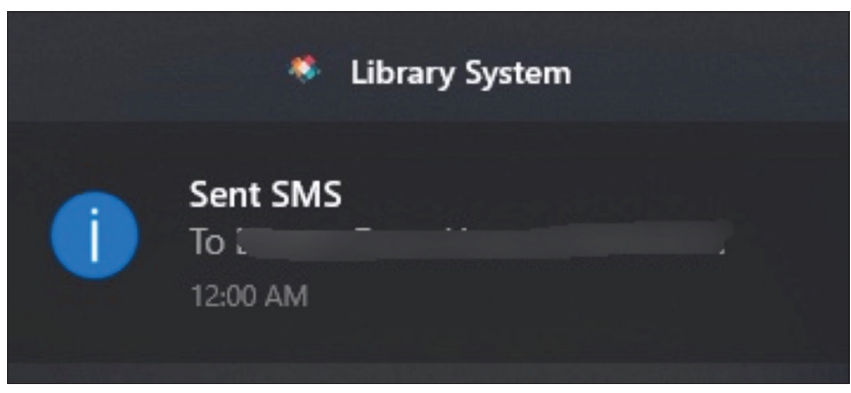

Fig. 21. Send SMS notification.

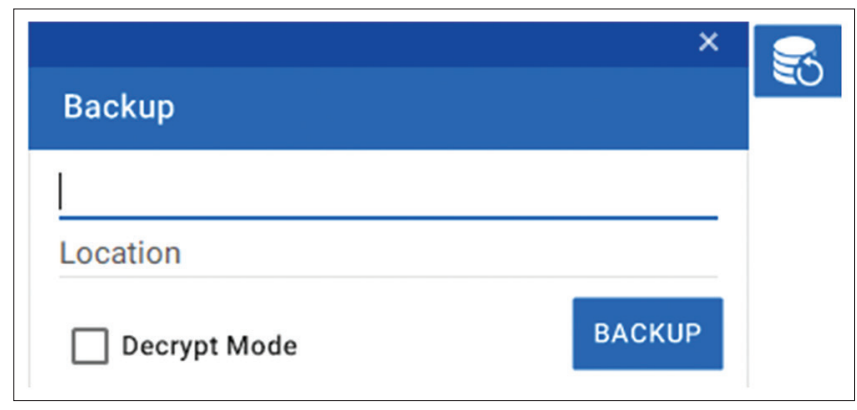

Fig. 22. Backup system.

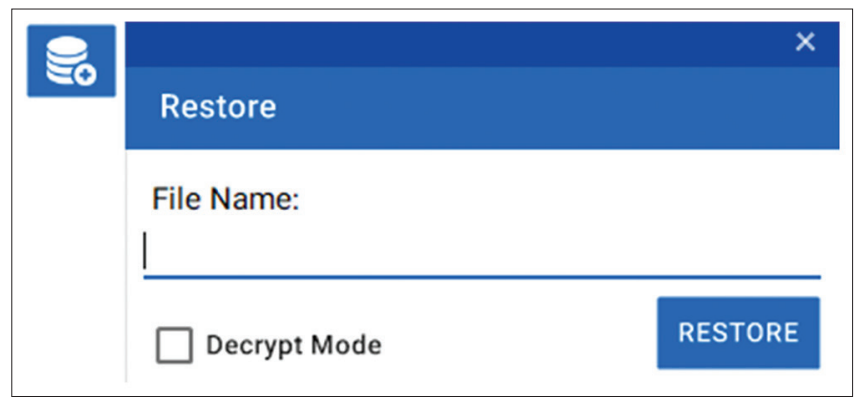

Fig. 23. Restore system.

TABLE 1: Time consumed in borrowing process of references

\begin{tabular}{lcc}
\hline Borrowing process & Single reference & 10 references \\
\hline Manual system & $1 / 2 \min [20]$ & $10 \min [20]$ \\
Library software & $1 \mathrm{~min}[20]$ & $5 \min [20]$ \\
RFID system & $15 \mathrm{~s}$ & $2.5 \mathrm{~min}$ \\
\hline
\end{tabular}

we can check to decrypt mode for did not encrypt the backup. Fig. 22 shows backup system.

\subsubsection{Restore system}

We can restore the system database by choose file name and check to decrypt mode for decryption the data that we want to display on the system, which is previously encrypted. Restore system shown in Fig. 23.

\section{RESULTS AND DISCUSSION}

We have proposed an IoT library system using RFID and GSM technologies. This system can manage all RFID readers connected to it and detect any reference, by its RIF tag, in any position inside the library. No references without permission cab are taken outside the library. Also inside the library, references can be moved according to their category, for example, a read-only reference cannot be moved to outside the specific room. Our system helps librarian in decreasing time needed to rearrange references and also in monitoring the movement of references. Also uses can borrow references without need any librarian help, but this feature is limited to those references allowed to be borrowed outside the library. The time spent for particular reference and 10 references in others system such as manual system and library software system will describe in Table 1, also the time spent in RFID system will test. In Table 1, we find that use RFID system in library will decrease time consumed of borrowing process comparing with the other systems.

\section{CONCLUSION}

The smart IoT technology in libraries is in the initial stage and currently evolving, therefore, there is a need for librarians to be trained in this technology while the IoT technology is more accepted, adopted, and available easily. RFID technology is used for tracing the references location, store, and fetch information rapidly. Implementation RFID in libraries has been discussed. All the processes such as issuing, reissuing returning references, references searching processes, and finds a misplaced reference position can be done quickly using RFID in library. References are now more easily traceable; enhance using of resources, and renewing of manual reference keeping. The main advantages of implementation of RFID-based LMS are a line of sight which is not mandatory, reduces manual intervention, reduces manual errors, and accesses to references faster. RFID-based LMS would increase the speed of operation as issuing, returning back, and retrieve references information. In this paper, the 
references search and location system on the library shelf are studied and designed. The hardware is designed in a new design that used for university library system. The test results of the system are demonstrated. The results show that the design of the system based on RFID can achieve easily reference searching and positioning function, and the system has a user-friendly interface. Moreover, to a certain extent, the system can help the librarian in management.

\section{REFERENCES}

[1] H. Ahmad. "Rfid technology in libraries: A case study of allama iqbal library, university of Kashmir". Journal of Indian Library Association, vol. 52, no. 4, pp. 109-119, 2016.

[2] A. C. Polycarpou, T. Samaras and J. N. Sahalos. An RFIDbased Library Management System Using Smart Cabinets: A Pilot Project. The $8^{\text {th }}$ European Conference on Antennas and Propagation, United States, pp. 2-4, 2014.

[3] Balasaheb, S. B. Raju, S. S. Rajabhau, A. B. Patil and P. A. Venencia. "Performance of Rfid technology at KS Goa state central library: A case study". Studies in Indian Place Names, vol. 40, no. 49, pp. 622-634, 2020.

[4] J. L. Liu and L. Zhu. "Library Intelligent Bookshelf Positioning System Research." In: $4^{\text {th }}$ International Conference on Mechatronics, Materials, Chemistry and Computer Engineering, Atlantis Press, Thailand, pp. 1237-1242, 2015.

[5] Y. Liu, "Design and Implementation of a Library Management System Based on RFID". In: The 2015 International Conference on Software Engineering and Information Technology, Indiana State University, Indiana, USA, pp. 2-4, 2016.

[6] V. Sivasankar, E. Soundararajan, and S. Rajeswari. "Challenges and impacts of RFID technology in a research library". In: Advances in Communication Systems and Networks, Springer, Berlin, Germany, 2020.

[7] M. Dhanalakshmi and U. Mamatha. "RFID Based Library Management System". pp. International Journal of Innovative Research in Advanced Engineering, vol. 1, no. 2, pp. 227-234, 2009.

[8] B. T. Venkatesh and J. Priya. "RFID: The big player in the libraries of the future". The Electronic Library, vol. 29, no. 1, pp. 36-51,
2011.

[9] W. M. Shamsudin, T. M. Win and M.J.E Salami. "RFID-Based Intelligent Books". IEEE Xplore, United States, 2007.

[10] M. Tajabadi and S. V. Azhari. "A Hybrid Privacy-preserving Mutual Authentication Protocol for RFID Traffic Management". ICEE, United States, pp. 1889-1894, 2019.

[11] G. Sethi and A. Dharani. "Challenges of radio frequency identification technique". Asset Works, vol. 3, no. 11, pp. 51-55, 2012.

[12] M. N. Mohammed, W. Muhamad, A. Wan, M. A. M. Ali, O. I. AlSanjary, and L. Raya. "Study on RFID based book tracking and library information system". In: 2019 IEEE 15 th International Colloquium on Signal Processing and Its Applications, IEEE, Malaysia, pp. 235-238, 2019.

[13] G. Ramu and Z. Mishra. "Hardware implementation of piccolo encryption algorithm for constrained RFID application”. In: 2019 $9^{\text {th }}$ Annual Information Technology, Electromechanical Engineering and Microelectronics Conference, IEEE, India, pp. 85-89, 2019.

[14] V. Pujari and B. Gadgay. "Smart library system using loT". International Journal for Research in Applied Science and Engineering Technology, vol. 6, no. 7, pp. 471-476, 2018.

[15] M. Mohammadi, M. Yegane, C. Library and Q. Branch. "IOT : Applied new technology in academic libraries". In: International Conference on Distributed Computing and High Performance Computing (DCHP 2018) 25 $25^{\text {th }}-27^{\text {th }}$ November, 2018, Qom, At University of Qom, Qom, pp. 1-12, 2018.

[16] A. K. Sharma. "Implementation of Rfid Technology in Library: A case study in UPES library". Library Philosophy and Practice (E-Journal), vol. 7, pp. 70-79, 2017.

[17] L. Philosophy, R. S. Kumar and K. Kaliyaperumal. "Applications of GSM technology for documents identification in a library system". International Journal of Academic Library and Information Science, vol. 2, no. 1, pp. 1-6, 2016.

[18] H. Sun and K. Chen. "A proposed model for library stacks management". Library Collections Acquisitions and Technical Services, vol. 36, no. 1-2, pp. 24-29, 2012.

[19] L. Li. "Designing and Implementation of University Library Automatic Management System," In: Pervasive Computing and the Networked World, International Conference, ICPCA-SWS, Istanbul, Turkey, pp. 241-247, 2014.

[20] N. Singh. "Deploying RFID Techniology in Management of Library Activities-a Case Study of College Library". Tamil Nadu Agricultural University, Tamil Nadu, pp. 331-334, 2013. 